Review of

ECONOMICS

and
Review of Economics and Institutions

ISSN 2038-1379 DOI:10.5202/rei.v10i1.286

Vol. 10 - No. 1, Spring-Summer 2019 - Article 2

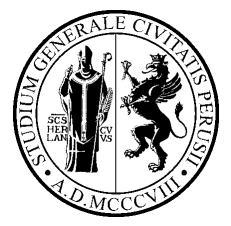

www.rei.unipg.it

\title{
The Effect of Temporary Parental Benefit on Children's Antibiotics Use: Evidence from a Natural Field Experiment
}

\author{
Linnea Wickström \\ Östervall ${ }^{凶}$ \\ Lund University
}

\author{
Annika Hahlin \\ Strama Stockholm
}

Astrid Lundevall

Strama Stockholm

\begin{abstract}
Prudent use of antibiotics is important to delay the spread of resistance. This paper analyses the effect on children's antibiotics use of a reform of the temporary parental benefit in Sweden. The reform increased the maximum compensation for this benefit. The level of compensation for social security may affect the propensity of a patient or parent to push for a prescription for antibiotics, as a less generous compensation makes it more expensive to be absent from work and since there is widespread overconfidence in the effectiveness of antibiotics. Using municipality level data, we show that the reform resulted in a reduction in children's antibiotics use by about five per cent. The result is fairly robust to alternative empirical strategies, suggesting that welfare policies can have important indirect effects that should be taken into account.
\end{abstract}

JEL classification: $118, \mathrm{H} 51, \mathrm{~J} 22$

Keywords: Antibiotics use; Social security; Temporary parental leave; Natural experiment; Resistance

Acknowledgments: Thanks to Charlotta Boström, Maria Cheung, Astri Muren, Jakob Svensson, and Conny Wollbrant for valuable comments. Linnea Wickström Östervall gratefully acknowledges funding from The Jan Wallander and Tom Hedelius Foundation. The Foundation has had no influence on any part of the design and analysis for this study. All mistakes are our own.

$\triangle$ Address: Lund University, Department of Clinical Sciences, Unit for Health Economics, Medicon Village, Building 301, level 5, S-223 81 Lund, Sweden. Tel:+46 708 257193. Mail: linneawo@gmail.com

\section{Recommended Citation}

Wickström Östervall, L., Hahlin, A., Lundevall, A. (2019). Effect of Temporary Parental Benefit on Children's Antibiotics Use: Evidence from a Natural Field Experiment. Review of Economics and Institutions, 10(1), Article 2. doi: 10.5202/rei.v10i1.286

Retrieved from http://www.rei.unipg.it/rei/article/view/286 


\section{Introduction}

This paper explores the effect on children's antibiotics use of a reform of the temporary parental benefit in Sweden. Welfare benefits may influence how eager the patient or parent is to ask for a prescription for antibiotics. Less generous sickness benefits, coupled with a widespread overconfidence in the effectiveness of antibiotics, may increase the demand for antibiotics. ${ }^{1}$ Overuse of antibiotics, in turn, leads to a faster spread of resistance, with important consequences for public health.

Antimicrobial resistance is an important policy issue at both international and national level. The discovery of antibiotics is one of the most important breakthroughs in medical history, and revolutionized the treatment of patients with bacterial infections. Antibiotics have contributed to reducing the mortality and morbidity from bacterial infections, and have become essential in modern medicine. Without them, procedures such as transplantation, chemotherapy for cancer and orthopaedic surgery could not be performed. Misuse and overuse of antibiotics, however, have resulted in the emergence of resistant bacteria (Barbosa and Levy, 2000). Prudent use of antibiotics can limit the spread of resistant bacteria, and help securing effective antibiotics for future generations. Since 1998 the World Health Assembly (WHA, the decision-making body of the World Health Organization, WHO) has adopted several resolutions, with recommendations to members on prudent use of antibiotics, to delay the spread of resistance (WHO, 2001; WHO, 2014). Unfortunately, many prescribers, patients and parents tend to overestimate the effect of antibiotics in non-severe bacterial infections leading to excessive use. It is estimated that in as much as 50 per cent of the cases antibiotics are used when not needed, or in the wrong - and hence inefficient - dose (CDC, 2013). ${ }^{2}$

We explore the effect on children's antibiotics use of a more generous compensation for temporary parental leave to care for a sick child. We exploit an increase in the cap for this benefit, for exogenous variation in the level of compensation. Two different approaches to a difference-in-difference estimation over time and across municipalities are employed, in addition to a triple difference over time and across municipalities as well as age groups. All results support the hypothesis that an increase in the maximum amount of compensation reduces antibiotics use among children of relevant ages, if their parents are plausibly affected by the reform.

Our results indicate that the increased benefit cap led to a reduction by about five per cent in antibiotics use among children in municipalities where mean income is at or above the old cap; i.e. in municipalities where

\footnotetext{
1 For evidence on overconfidence see e.g. Mainous et al. (1997); for overconfidence in Sweden in particular, see e.g. André et al. (2010).

2 This estimate is for the US. In Sweden the figures are probably a bit less gloomy, but still about 30-40 per cent.
} 
parents were more likely affected by the reform. Similar or larger effects are estimated in alternative specifications. These results are driven by a very large effect among pre-schoolers, whose antibiotics use is reduced by about eighteen per cent, relative to older children.

\section{Background and Related Literature}

This paper contributes to the literature on the effects of social benefits and optimal policy. There is a large literature within economics analysing unemployment benefits, and a small but growing literature on sickness benefits (see Fredriksson and Holmlund, 2006 for a review of research on unemployment benefits; and Hall and Hartman, 2010; Johansson and Palme, 2005; Ziebarth and Karlsson, 2010, 2014 for sickness benefits). ${ }^{3}$ These studies have in common that the direct effects - typically on labour supply and/or absenteeism - are estimated. When addressing the question on how optimal levels of compensation in social security benefit systems can be determined, we should also consider which factors should be taken into account when striking the balance between compensating for income loss and avoiding excess use. There may be additional, indirect effects, with important policy implications. This paper addresses one particular such factor: The level of compensation for social security may affect antibiotics use. This is an important indirect effect, as prudent use of antibiotics is vital to delay the spread of resistance.

Previous studies on the effect of (changes in) social benefits on sick leave/absenteeism focus on adult workers' absence from work and usage of benefits. Typical outcomes studied are number of sick spells and duration of spells. In general the results are in line with the theoretical prediction, i.e. increased usage when benefits become more generous and vice versa. (Hall and Hartman, 2010; Johansson and Palme, 2005; Ziebarth and Karlsson, 2010, 2014.) This paper is related, but differs in its focus on an indirect effect of a compensation program, namely the effect on children's antibiotics use of a reform of the temporary parental benefit.

Earlier studies in Sweden have shown large differences in antibiotics use across socio-economic strata. Socio-economic factors influence antibiotics use, in particular among children aged 0-6 years, with higher antibiotics use in areas with high average family income and a high employment rate, than in areas with large shares of blue-collar workers, people with foreign background and recipients of social benefit (Henricson et al., 1998). These findings are consistent with the hypothesis that the level of compensation in welfare benefits can be an important determinant for the use of antibiotics. In particular, a cap for the level of compensation implies relatively lower level of compensation, for those with higher incomes. Fogelberg (2013) find that increased competition for

\footnotetext{
3 Krueger and Meyer's chapter (2002) "Labor supply effects of social insurance" in Handbook of Public Economics does not cover sick leave benefits.
} 
patients between clinics increases antibiotics prescriptions. This suggests that at least to some extent overdemand does translate into overuse.

\section{Institutional Background}

In Sweden, a parent or other caregiver can receive temporary parental benefit, when staying home from work to take care of a sick child aged less than 12 years. An important restriction is that parents may not use the temporary parental benefit for a sick child, if they are already on regular parental leave to care for this child. Various aspects of this benefit, such as maximum number of days per year, level of compensation, and rules for receiving them have been altered several times since they were first introduced in $1974 .{ }^{4}$ We focus on a recent change in the compensation. The compensation is about 80 per cent of the so-called sickness benefit qualifying income - basically annual income - up to a cap. The cap is expressed in terms of a price base amount, which is adjusted annually. The price base amounts for the years 2005 and 2006 are presented in Table 1 July 12006 the cap was raised, from seven point five, to ten times the price base amount (this corresponds to an increase from SEK 297,750 to SEK 397,000 per annum). Due to a change in government, as well as increased concern about misuse, this raised cap was only in effect for six months; January 12007 it was reduced to the original seven point five times the price base amount. The raised cap affected anyone with a monthly salary of more than SEK 24,812.50 (in 2006). The impact of the reform on the level of compensation was largest for those with an income above the old cap and at or below the new cap, i.e. with a monthly salary in the range from about SEK 24,800 to SEK 33,100.

Table 1 The Price Base Amount Annually for Years 2005-2006

\begin{tabular}{cc}
\hline Year & Price base amount (SEK) \\
\hline 2005 & 39,400 \\
2006 & 39,700 \\
\hline
\end{tabular}

Antibiotics are by prescription only in Sweden.

\section{Empirical Strategy}

The main hypothesis is that the increase in the maximum amount of compensation reduces demand for antibiotics to children aged 1-11 years, if their parents - or at least one of their parents - are affected by the reform, such that the level of compensation is increased, when they stay home from work to take care of a sick child.

\footnotetext{
4 For an overview (in Swedish) see Swedish Social Insurance Agency (2007).
} 
It should be noted that we may find an effect on children's antibiotics use regardless of any change in the number of days their parents claim this temporary parental benefit, when the compensation level changes. While effective antibiotics are vital to cure more serious infections, they typically have negligible or even no effect on recovery time in cases of uncomplicated infections (Little et al., 1997; Little et al., 2005; Neumark et al., 2007; Williamson et al., 2007). Hence, on average we would expect little or no effect on the number of sick days, and we may see a decrease in children's antibiotics use independently of any change in number of days they are home sick. In other words, since parents typically believe that antibiotics will lead to a more speedy recovery, they demand antibiotics for their children, when staying home to take care of sick children is costly. The increased cap makes it less costly to stay home, for parents affected by the reform. However, since antibiotics typically have no or only negligible effect on the duration of illness in case of common infections, there will be no, or only very limited, effect on the number of sick days.

A general problem, when studying how social benefits impact various decisions, is to isolate a causal effect. Typically, compensation level is tied to the worker's earnings history, which is likely to be highly correlated with taste for work, e.g. ambitions typically manifested in exerted effort, interest in signalling to the employer that work is prioritized, and actual priorities over work - leisure. Hence, it is hard to disentangle the effect of the benefits, from direct effects of different tastes for work (see e.g. the discussion in Pettersson-Lidbom and Skogman Thoursie, 2013). To overcome this identification problem, we exploit a natural experiment, and employ a difference-in-difference strategy on municipality level data. In 2006 the cap for the level of compensation, when staying home to take care of a sick child, was raised in Sweden. As the reform only affected parents with incomes at or above the old cap, we can exploit the variation over time, between parents affected and not affected by the reform.

With this municipality level data, we estimate the effect of the reform comparing antibiotics use among children, whose parents are eligible for temporary parental benefit, in municipalities where mean income is at or above the old cap, to that in municipalities with mean income below the old cap. This binary treatment indicator gives us the effect of the reform in municipalities where parents are more likely affected by the reform. In an alternative specification, we estimate how antibiotics use varies with the share of working age population with an income at or above the old cap. This approximately continuous treatment variable serves as a proxy for the extent to which parents are affected by the reform. It gives us an estimate of what the effect would be, if a municipality went from a zero share to a share equal to one. We multiply this estimate with the mean share, to get an estimate of the effect of the reform for municipalities with (close to the) average share of population with an income at or above the old cap. This approximately continuous treatment variable might give a better estimate of the general effect of the reform. However, as will 
become clear below, the estimates with these two different treatment variables are comparable.

Further, we also exploit the fact that older children are not affected, as their parents are no longer eligible for temporary parental leave, along with the proxy for the difference in the extent to which parents are affected by the reform, estimating the effect over time, across age groups and municipalities.

In our first approach, to estimate the causal effect of the increase in the cap on antibiotics use among children whose parents are eligible for temporary parental benefit, we estimate the following base specification on municipality level data:

$$
\ln \left[y_{m t}\right]=\alpha_{0}+\alpha_{1}\left[T_{m} \times \operatorname{POST}_{t}\right]+\alpha_{2} T_{m}+\alpha_{3} \operatorname{POST}_{t}+\mu_{m t}
$$

where $y_{m t}$ is prescriptions per child aged 2-11 years in municipality $m$ in time period $t, T_{m}$ is a dummy equal to one if mean income of the working age population in municipality $m$ is greater than or equal to seven point five price base amounts, and $P O S T_{t}$ is a dummy equal to one from July 2006. Municipality and monthly time fixed effects are subsequently added. Antibiotics use is typically higher during flu season. A dummy equal to one for the months October through March is included, to capture this seasonal pattern. As data is by age on New Year's Eve, children who are one year old at that point in time are typically still at home with a parent, and this group is thus excluded. Similarly, children who are twelve years old by New Year's Eve are excluded, as their parents are only eligible for temporary parental leave to care for them when they are ill till they turned twelve.

Using the shares of the working age population with incomes at or above the old cap, interacted with a dummy equal to one after the cap was raised, we estimate the following specification:

$$
\ln \left[y_{m t}\right]=\alpha_{0}+\alpha_{1}\left[\vartheta_{m} \times \operatorname{POST}_{t}\right]+\alpha_{2} \vartheta_{m}+\alpha_{3} \operatorname{POST}_{t}+\mu_{m t}
$$

where $y_{m t}$ is again prescriptions per child aged 2-11 years in municipality $m$ in time period $t . \vartheta_{m}$ is the share of the population in municipality $m$ that has an income in the category covering the relevant range of seven point five to ten price base amounts. ${ }^{5} P O S T_{t}$ as before is a dummy equal to one from July 2006. Municipality and monthly time fixed effects are included, along with the dummy for flu season.

\footnotetext{
${ }^{5}$ Data is only available for rather broad income categories. The category covering the relevant range is SEK 20,000-39,000 per month; this corresponds to an annual income in the range SEK 240,000- 468,000.
} 
Exploiting variation in how the reform affects different age groups, and in the proxy for the extent to which parents are affected by the reform, we relate the change in antibiotics use among children, whose parents are eligible for temporary parental benefit when they are sick, to that of older children, whose parents are not. We estimate the following specification:

$\ln \left[y_{m t}\right]=\alpha_{0}+\alpha_{1}\left[I_{g} \times \vartheta_{m} \times \operatorname{POST}_{t}\right]+\alpha_{2} I_{g}+\alpha_{2} \vartheta_{m}+\alpha_{3} \mathrm{POST}_{t}+\mu_{m t}$

where $y_{m t}$ is prescriptions per child in municipality $m$ time period $t$, and $I_{g}$ is an indicator variable equal to one for children aged eleven years or less. ${ }^{6}$ As above, $\vartheta_{m}$ is the share of the population in municipality $m$ that has an income in the category covering the relevant range of seven point five to ten price base amounts, and $P O S T_{t}$ is a dummy equal to one from July 2006. Again, municipality and monthly time fixed effects are included, along with the dummy for flu season and age fixed effects capturing systematic variation in the prevalence of infections.

To tease out where the effect is strongest, this is also estimated separately for preschool children and school aged children, whose parents are still eligible for temporary parental leave, versus older children.

That is, we estimate differences-in-differences over time and across municipalities (equation 1 and 2) and a triple difference, over time and across age groups as well as municipalities (equation 3).

\section{Measures}

Data on prescriptions by age group and municipality is from the National Board of Health and Welfare. ${ }^{7}$ This prescription data is available by month from July 2005. We use data for the period July 2005 - December 2006. Children aged 2-11 years old are included in the main analysis. We exclude children aged one year, since parents in Sweden are typically on parental leave at least the first year, often 15-18 months. Parents cannot be on temporary parental leave to take care of a sick child, if they are already on (regular) parental leave to care for that child. When children turn twelve, parents are no longer eligible for temporary parental leave to care for them when they are ill. Hence, we exclude also children aged twelve and up.

\footnotetext{
6 The youngest children are once more excluded, as they are special cases: In Sweden parents are typically on parental leave at least the first year, often 15-18 months. Parents cannot be on temporary parental leave to take care of a sick child, if they are already on (regular) parental leave to care for that child.

7 The National Board of Health and Welfare is a government agency in Sweden under the Ministry of Health and Social Affairs; now part of The Public Health Agency of Sweden.
} 
Data on income, demographics, unemployment, and price base amount is from Statistics Sweden. Income and demographics are available by municipality; unemployment is only available by county. Statistics Sweden also provides a key to which municipalities belong to which county. The data from Statistics Sweden is available by year. Income data is only available for rather broad categories. The category covering the relevant range is SEK 20,000-39,000 per month; this corresponds to an annual income in the range SEK 240,000-468,000.

\section{Descriptive Statistics}

As evident from Table 2, antibiotics prescriptions to children aged 1-11 years on average increased both in municipalities with mean income below and at or above the old cap. The increase was about 2.7 per cent for municipalities with mean income below the old cap, and two per cent for those with mean income at or above it. However, this figure will naturally be higher for municipalities with more children. Therefore, we divide the number of prescriptions to children aged 1-11 years (by municipality and month) by the number of children in this age group. Employing this adjustment the figures are more comparable, and we note that while there was an increase in both groups, the increase was about five per cent for the municipalities with mean income below the old cap, and less than two per cent (about 1.8 to be more precise) in municipalities with mean income at or above the old cap.

Table 2 Mean Antibiotics Prescriptions

\begin{tabular}{|c|c|c|}
\hline \multicolumn{3}{|c|}{ Mean antibiotics prescriptions for children aged 1-11 years } \\
\hline Municipalities with mean income & Before reform & After reform \\
\hline$<$ old cap & 146 & 150 \\
\hline$\geq$ old cap & 300 & 306 \\
\hline \multicolumn{3}{|c|}{ Mean antibiotics prescriptions per child aged 1-11 years } \\
\hline$<$ old cap & 0.0358 & 0.0376 \\
\hline$\geq$ old cap & 0.0482 & 0.0491 \\
\hline
\end{tabular}

Mean antibiotics prescriptions for children aged 1-11 years fall 2005 and fall 2006 for municipalities below and above the old cap, respectively.

Municipalities with mean income below the new cap on average have significantly fewer children aged 1-5 years as well as 1-11 years, despite no significant difference in overall population, and also no significant difference in number of older children (aged 12-17 years) (see Table 3). Mean unemployment is significantly lower in the municipalities with mean income at or above the new cap (see Table 3). This is not surprising, as mean income and unemployment are negatively correlated.

Key to identifying a causal effect of the reform on children's antibiotics use is that municipalities with mean income at or above the old cap, and 
municipalities with mean income below the old cap, display parallel trends in prescriptions prior to the reform. This is not trivial to assess, as data on prescriptions is only available from July 2005, i.e. but a year prior to the reform. A further complication is the seasonal variation, with much higher use during the flu season. As can be seen in Figure 1, trends are roughly parallel. It is also clear from this graph that any significant effect of the reform would be due to a decline in prescriptions July and August 2006 in municipalities with mean income at or above the old cap, as beyond that, trends are parallel again. This is somewhat odd, and should be kept in mind for the discussion about policy implications.

Table 3 Means by Municipalities with Mean Income Below and Above the New Cap,

\begin{tabular}{lccc}
\multicolumn{4}{c}{ Respectively } \\
\hline Variable & Mean < old cap & Mean $\geq$ old cap & Diff \\
\hline & & & \\
Population & 30931 & 40663 & -9732 \\
& $(3602)$ & $(8567)$ & $(9293)$ \\
\# of children aged 1-5 & 1649 & 2887 & $-1238^{*}$ \\
years (pre-schoolers) & $(199)$ & $(613)$ & $(644)$ \\
\# of children aged 1-11 & 3669 & 6213 & $-2544^{*}$ \\
years & $(410)$ & $(1293)$ & $(1357)$ \\
\# children aged 12-17 & 2552 & 3578 & -1027 \\
years & $(242)$ & $(731)$ & $(770)$ \\
Unemployment (\%) & 8.03 & 7.14 & $0.896^{* * *}$ \\
& $(0.0703)$ & $(0.238)$ & $(0.248)$ \\
\hline
\end{tabular}

Data from 2005, i.e. prior to the reform, is used for these comparisons. Two sample t-test with unequal variances. $\left.{ }^{* * *}\right)$ Significant at least at $1 \%$ level Ha: diff $\neq 0 \operatorname{Pr}(|\mathrm{T}|>|\mathrm{t}|)=<0.01^{*}$ ) Significant at $10 \%$ level Ha: diff $\neq 0 \operatorname{Pr}(|\mathrm{T}|>|\mathrm{t}|)=<0.1$. Standard errors in parenthesis.

As mentioned above, when employing the proxy for the extent to which parents are affected by the reform, we will need to adjust the estimated coefficients to get meaningful estimates. Mean and standard deviation for the share of the working age population with an income in the category covering the old cap as well as the share with income in the category covering the old cap and the next category up are used for these calculations. These are presented in Table 4. 
Figure 1 Parallel trend

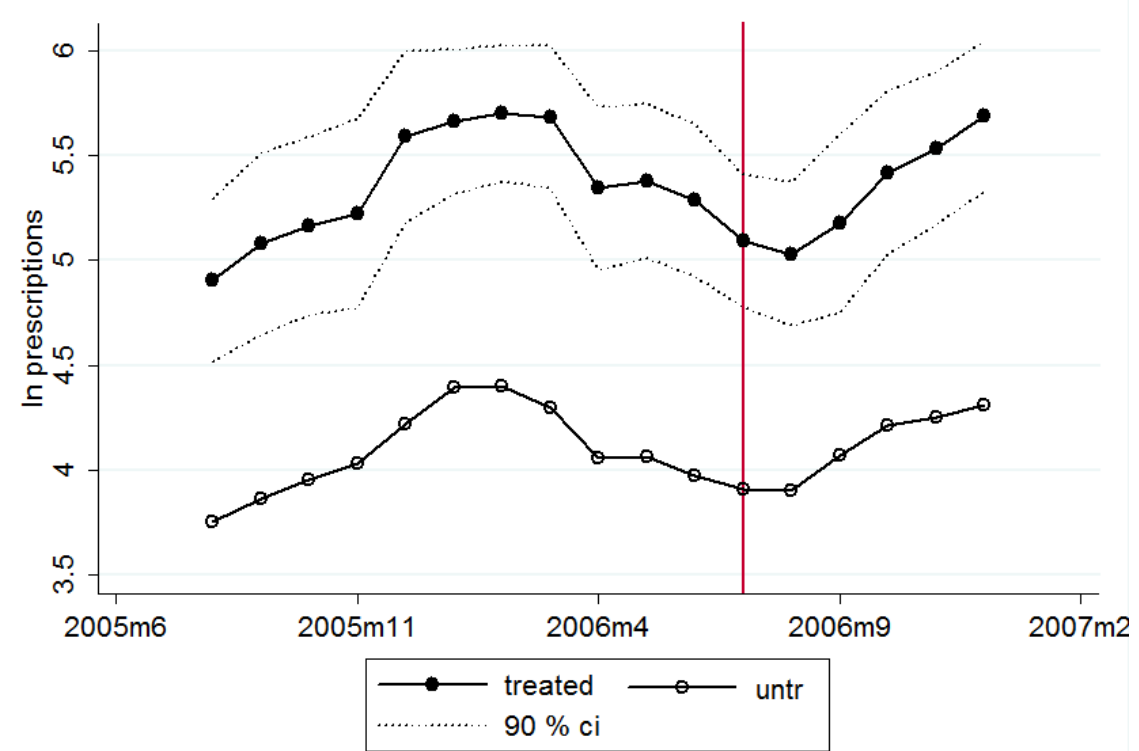

Regression coefficients from regressing In(prescriptions) on the binary treatment indicator separately for municipalities with mean income at or above the old cap (treated; indicator $=1$ ) and below the old cap (untreated; indicator=0) for each month July 2005-December 2006. Vertical line at July 2006, when the cap was increased

Table 4 Descriptive Statistics for Income Categories Affected

\begin{tabular}{lcccc}
\hline Share with income: & Mean & Std.dev. & Min & Max \\
\hline In only the category covering the old cap & 0.0177 & 0.00555 & 0.00884 & 0.0607 \\
In that and the next category up & 0.0355 & 0.00929 & 0.0205 & 0.100 \\
\hline
\end{tabular}

Mean, standard deviation, min, and max for share of the population with income in the category covering the old cap and including also the next category up for years 2005 and 2006.

\section{Results}

Below we present the results of estimations of the differences-in-differences over time and across municipalities (equation 1 and 2), and the triple difference, over time and across age groups as well as municipalities (equation 3).

\subsection{Difference-in-difference with Binary Treatment Indicator}

When employing the binary treatment variable equal to one for municipalities with mean income at or above the old cap, and estimating the effect of the raised cap of the benefit for temporary parental leave, we find that in the base specification the estimated effect is a reduction by 6.17 per cent in prescriptions per child (p-value 0.007) (see Table 5, column 1). Adding municipality and time fixed effects, as well as a dummy for flu season (equal to one for the months October through Mars) slightly reduces the absolute value of the estimated effect, but still it is a reduction 
by 5.39 per cent (p-value 0.009) (see Table 5, column 2). These are estimates of the effect of the reform, on children's antibiotics use, in municipalities where parents were more likely affected by the reform.

Table 5 Effect Estimated with Binary Treatment Indicator

\begin{tabular}{lcc}
\hline & $(1)$ & $(2)$ \\
VARIABLES & Prescriptions/child & Prescriptions/child \\
\hline TREATED & $\mathbf{0 . 0 6 1 7 ^ { * * * }}$ & $\mathbf{- 0 . 0 5 3 9 ^ { * * * }}$ \\
& $\mathbf{( 0 . 0 2 2 7 )}$ & $\mathbf{( 0 . 0 2 0 4 )}$ \\
flu_season & & $0.523^{* * *}$ \\
& & $(0.0299)$ \\
POST & $0.0466^{* * *}$ & \\
& $(0.0126)$ & \\
treat_binary & $0.348^{* * *}$ & \\
& $(0.0345)$ & yes \\
Municipality FE & no & yes \\
Time FE & no & 5,221 \\
Observations & 5,221 & 0.580 \\
R-squared & 0.018 & \\
\hline
\end{tabular}

Dependent variable is $\ln$ (prescriptions per child aged 2-11 years). Coefficient of main interest is that on TREATED, an interaction between the dummy POST equal to one from July 2006, when the cap is raised, and a dummy for mean income at or above the cap. Data on prescriptions by municipality and month July 2005 - December 2006 is used. Robust standard errors clustered by municipality in parentheses. ${ }^{* * *} \mathrm{p}<0.01, * * \mathrm{p}<0.05, * \mathrm{p}<0.1$

\subsection{Difference-in-difference with Approximately Continuous Treatment Variable}

Next we turn to the approximately continuous treatment variable, using the share of working age population with an income in the category covering the old cap (Table 6, column 1), and including also the next category above the cap (Table 6, column 2). The estimates are significant at the ten and the five per cent levels, respectively ( $p$-values 0.054 and 0.036 ) (Table 6, columns 1 and 2).

These coefficients are estimates of the effect of the reform, on children's antibiotics use, if going from a zero share of working age population with an income in this/these category/categories to a share equal to one. To get more relevant estimates, we can compare at mean shares. Mean share of working age population with an income in the category covering the old cap is about 0.0177. Mean share with an income in this and the next category up is about 0.0355 . This gives estimated effects at mean shares of about -5.63 per cent and -6.89 per cent, respectively. I.e. these estimates are roughly comparable in magnitude to those reported in Table 5. A one standard deviation increase, in the share of working age population with 
an income in the category covering the old cap, is associated with a reduction by 1.77 per cent in children's antibiotics use. A one standard deviation increase, in the share of working age population with an income in this and the next category up, is associated with a decrease by 1.80 per cent. I.e. the effect is mainly driven by those with an income in the category covering the old cap, which is expected, as this is the category for which the reform had the largest impact on compensation level. ${ }^{8}$

Table 6 Effect Estimated with Approximately Continuous Treatment Variable

(1)

\begin{tabular}{lcc} 
VARIABLES & Closest inc cat. & At and above \\
\hline share_POST & $\mathbf{- 3 . 1 8 3 ^ { * }}$ & $\mathbf{- 1 . 9 3 5 ^ { * * }}$ \\
& $\mathbf{( 1 . 6 4 6 )}$ & $\mathbf{( 0 . 9 1 9 )}$ \\
flu_season & $0.577^{* * *}$ & $0.589^{* * *}$ \\
& $(0.0455)$ & $(0.0479)$ \\
Municipality FE & yes & yes \\
Time FE & yes & yes \\
Observations & 5,221 & 5,221 \\
R-squared & 0.581 & 0.581 \\
\hline
\end{tabular}

Dependent variable is $\ln$ (prescriptions per child aged 2-11 years). Coefficient of main interest is that on share_POST, which is an interaction between the dummy POST, equal to one from July 2006, when the cap is raised, and the share of working age population with an income in the category closest to the old cap (column 1 ) or including also those in the next category above the old cap (column 2). Data on prescriptions by municipality and month July 2005 - December 2006 is used. Robust standard errors clustered by municipality in parentheses. ${ }^{* * *} p<0.01, * * p<0.05$, * $\mathrm{p}<0.1$.

\subsection{Triple Difference with Older Children as Comparison Group}

Turning now to our third strategy, we exploit the difference in impact for different age groups, and differences in share of parents potentially affected by the reform. I.e. we estimate equation 3, with the shares of working age population with an income in the category covering the old cap (Table 7, column 1), and including also the next category above the cap (Table 7, column 2). We find a strong and significant effect of the reform. The estimates are significant at the one per cent level (both p-values are zero to the fourth decimal). (See Table 7, columns 1 and 2.)

\footnotetext{
8 The income category covering the old cap includes everyone who went from less than 80 per cent to an 80 per cent compensation level. In the next category up everyone gets a higher level of compensation, but it remains less than 80 per cent of their incomes, as they all earn more than the new cap.
} 
Table 7 Effect Estimated with Approximately Continuous Treatment Variable and Comparison Group

(1)

\begin{tabular}{lcc} 
VARIABLES & Closest inc cat. & At and above \\
\hline & & \\
triple interaction & $\mathbf{- 4 . 6 5 3 ^ { * * * }}$ & $\mathbf{- 2 . 5 1 5 ^ { * * * }}$ \\
& $\mathbf{( 1 . 0 0 2 )}$ & $\mathbf{( 0 . 5 0 8 )}$ \\
flu_season & $0.560^{* * *}$ & $0.565^{* * *}$ \\
& $(0.0389)$ & $(0.0389)$ \\
Municipality FE & yes & yes \\
Time FE & yes & yes \\
Age FE & yes & yes \\
Observations & 78,300 & 78,300 \\
R-squared & 0.272 & 0.272 \\
\hline
\end{tabular}

Dependent variable is In(prescriptions per child). Coefficient of main interest is that on triple interaction, which - as the name suggests - is a triple interaction between the dummy POST, equal to one from July 2006, when the cap is raised, a dummy equal to one for age groups affected by the reform (i.e. children aged 2-11 years), and the share of working age population with an income in the category closest to the old cap (column 1) or including also those in the next category above the old cap (column 2). Data on prescriptions by municipality and month July 2005 - December 2006 is used. Robust standard errors clustered by municipality in parentheses. ${ }^{* * *} p<0.01,{ }^{* *} p<0.05,{ }^{*} p<0.1$

These are estimates of the effect for children, whose parents are eligible for temporary parental leave, relative to children whose parents are not (because the children are too old), if the share of working age population with an income in the affected category/categories goes from zero to one. When multiplied by the mean shares we get estimates of about -8.24 and -8.93 per cent, respectively. I.e. antibiotics use is about eight per cent less among children, whose parents are eligible for temporary parental leave, in municipalities with (close to) mean share of working age population with an income in the category covering the old cap for this benefit. It is close to nine per cent less for eligible children, in municipalities with (close to) a mean share of working age population with an income in the category covering the old cap and the next category up. A one standard deviation increase in the share of working age population with an income in the category covering the old cap, is associated with a reduction by 2.56 per cent, while a one standard deviation increase in the share of working age population with an income in this and the next category up, is associated with a decrease by merely 2.34 per cent. I.e. the effect now seems to entirely be driven by those with an income in the category covering the old cap. These estimates are somewhat larger in absolute value, but roughly in the same ballpark, as those obtained with the difference-in-differences over time and across municipalities (only). 
Exploring further if the effect is driven by particular age groups, among children whose parents are eligible for temporary parental leave, we estimate the effect separately for pre-schoolers (aged 2-5 years) and for primary school children (aged 6-11 years), still using older children (aged 13-17 years) as comparison group. Including only pre-schoolers and older children, and estimating equation 3 , the estimate is -10.33 (p-value is zero to the fourth decimal) (see Table 8, column 1). This translates to about 18.3 per cent less antibiotics prescriptions per pre-schooler, relative to older children, whose parents are no longer eligible for temporary parental leave, at mean share of working age population with an income in the category covering the old cap. A one standard deviation increase, in the share of working age population with an income in the category covering the old cap, is associated with a reduction by 5.73 per cent.

Table 8 Effect estimated separately by age group, with approx. continuous treatment variable and comparison group

\begin{tabular}{lcc}
\hline & $(1)$ & $(2)$ \\
VARIABLES & $\mathbf{2 - 5}$ vs $\mathbf{1 3 - 1 7}$ & $\mathbf{6 - 1 1}$ vs 13-17 \\
\hline triple interaction & $\mathbf{- 1 0 . 3 3 * * *}$ & $\mathbf{- 1 . 1 1 6}$ \\
& $\mathbf{( 1 . 2 9 6 )}$ & $\mathbf{( 1 . 1 2 3 )}$ \\
flu_season & $0.659 * * *$ & $0.373 * * *$ \\
& $(0.0389)$ & $(0.0413)$ \\
Municipality FE & yes & yes \\
Time FE & yes & yes \\
Age FE & yes & yes \\
Observations & 46,980 & 57,420 \\
R-squared & 0.296 & 0.234 \\
\hline
\end{tabular}

Dependent variable is $\ln$ (prescriptions per child). Coefficient of main interest is that on triple interaction, which - again as the name suggests - is a triple interaction, between the dummy POST, equal to one from July 2006, when the cap is raised, a dummy equal to one for age groups affected by the reform (i.e. children aged 2-11 years), and the share of working age population with an income in the category closest to the old cap. In the first column only pre-schoolers (aged 2-5 years) and older children (aged 13-17 years) are included. In column 2 pre-schoolers are excluded. Data on prescriptions by municipality and month July 2005 - December 2006 is used. Robust standard errors clustered by municipality in parentheses. ${ }^{* * *} p<0.01,{ }^{* *} p<0.05,{ }^{*} p<0.1$

When instead excluding pre-schoolers, and estimating equation 3 separately for children aged 6-11 years relative to older children, we find no significant effect (see Table 8, column 2). I.e. the effect found in Table 7 is clearly driven by pre-schoolers, who also tend to be more prone to infections, and typically consume more antibiotics than older children. Besides the higher burden of infections among pre-schoolers, these are also children who are too young to be left alone, even for a short period of time, implying that, for these children, a parent or other care-giver will 
have to stay home from work to care for them, for the entire duration of their illness. ${ }^{9}$

\subsection{Robustness}

To test the robustness, we run a placebo test. We do this by estimating a variant of equation 1, switching on a dummy in January 2006, and using data from July 2005 through June 2006, i.e. from the pre-reform period only. The coefficient on the interaction between a dummy equal to one from January 2006 and a dummy equal to one for municipalities with mean income at or above the old cap is positive and insignificant (see Table 9). This offers some support for the validity of the results presented above.

Table 9 Placebo Test on Data from Pre-reform Period

\begin{tabular}{lcc}
\hline VARIABLES & $(1)$ & $(2)$ \\
& Placebo Jan 2006 & Placebo Jan 2006 \\
\hline PLACEBO×treat_bi & $\mathbf{0 . 0 8 4 6}$ & $\mathbf{0 . 0 7 8 6}$ \\
flu_season & $\mathbf{( 0 . 0 5 1 7 )}$ & $\mathbf{( 0 . 0 4 8 7 )}$ \\
& & $0.508^{* * *}$ \\
PLACEBO & $0.277^{* * *}$ & $(0.0249)$ \\
& $(0.0150)$ & \\
treat_binary & $0.295^{* * *}$ & \\
& $(0.0403)$ & \\
Municipality FE & no & yes \\
Time FE & no & yes \\
Observations & 3,480 & 3,480 \\
R-squared & 0.109 & 0.626
\end{tabular}

Placebo test on data from pre-reform period, July 2005 through June 2006. Dependent variable is In(prescriptions per child aged 2-11 years). Coefficient of main interest is that on PLACEBOxtreat_bi, which is an interaction between the dummy PLACEBO equal to one from January 2006 and treat_binary, which is a dummy for mean income at or above the old cap. Robust standard errors clustered by municipality in parentheses. ${ }^{* * *} p<0.01,{ }^{* *} p<0.05,{ }^{*} p<0.1$

\section{Discussion and Concluding Remarks}

We explore the effect on children's antibiotics use of a more generous compensation for temporary parental leave to care for a sick child. We exploit an increase in the cap for this benefit, for exogenous variation in the level of compensation. Two different approaches to a difference-in-difference estimation over time and across municipalities are

\footnotetext{
9 Note to American readers: It is not illegal to leave children home alone in Sweden.
} 
employed, in addition to a triple difference over time and across municipalities as well as age groups. All results support the hypothesis that an increase in the maximum amount of compensation reduces antibiotics use among children of relevant ages, if their parents are plausibly affected by the reform.

Both difference-in-difference estimations yield similar results. We find effects ranging from -5.39 per cent to -6.89 per cent. This is a non-negligible effect. Exploiting variation over time, and across age groups, as well as municipalities, we also find a significant and strong effect. Relative to older children, antibiotics use is about eight to nine per cent less among children, whose parents are eligible for temporary parental leave, in a municipality with about mean share of working age population with an income in affected categories. This effect is mainly driven by children of preschool age; controlling for age specific effects capturing that younger children are generally more prone to infections, their antibiotics use is reduced by about eighteen per cent relative to older children.

Policy implications are not immediate. While the estimated effects are quite large, it is unclear if they represent only a short-term effect, or would be sustained in the long run. As noted in the discussion of Figure 1, the effect seems to be focused on only two months immediately following the implementation. Nonetheless, the consistency of results across specifications is still an indication that the level of compensation in social security benefits can have important indirect effects; in this case with urgent consequences for the possibility to limit antibiotics use and delay the spread of resistance. A limitation of our study is that we only have access to data at municipality level. Future work should aim at exploring the effect at household level and, if possible, look at a reform that is in effect for a longer period of time, allowing an investigation of more long-term effects, if any.

\section{CONFLICT OF INTEREST}

The authors declare that they have no conflict of interest.

\section{ETHICAL STATEMENT}

The data used for this project is at an aggregate level. Hence, the legislation for ethical review is not applicable.

\section{DATA AND COMPUTER CODE AVAILABILITY}

The data that support the findings of this study are available from The Public Health Agency of Sweden, but restrictions apply to the availability of these data, so they are not publicly available. Instructions for how other researchers can obtain the data, and all the information needed to proceed from the raw data to the results of the paper (including code) are however available from the authors on request and with permission of The Public Health Agency of Sweden. 


\section{References}

André, M., Vernby, A., Berg, J., Lundborg, C., 2010. A Survey of Public Knowledge and Awareness Related to Antibiotic Use and Resistance in Sweden. The Journal of Antimicrobial Chemotherapy, 65(6), 1292-1296

Barbosa, T.M., Levy, S.B., 2000. The Impact of Antibiotic Use on Resistance Development and Persistence. Drug Resistance Updates: Reviews and Commentaries in Antimicrobial and Anticancer Chemotherapy, 3(5), 303-311

CDC, US Department of Health and Human Services, 2013. Threat Report 2013: Antibiotic Resistance Threats in the United States, 2013. CS239559-B, available at http://www.cdc.gov/drugresistance/threat-report-2013/pdf/ar-threats-2013-508. pdf

Fredriksson, P., Holmlund, B., 2006. Improving Incentives in Unemployment Insurance: A Review of Recent Research. Journal of Economic Surveys, 20(3), 357-386

Fogelberg, S., 2013. Competition and Antibiotics Prescription. IFN Working Paper No. 949

Hall, C., Hartman, L., 2010. Moral Hazard among the Sick and Unemployed: Evidence from a Swedish Social Insurance Reform. Empirical Economics, 39(1), 27-50

Henricson, K., Melander, E., Mölstad, S., Ranstam, J., Hanson, B.S., Rametsteiner, G., Stenberg, P., Melander, A., 1998. Intra-urban Variation of Antibiotic Utilization in Children: Influence of Socio-economic Factors. European Journal Of Clinical Pharmacology, 54(8), 653-657

Johansson, P., Palme, M., 2005. Moral Hazard and Sickness Insurance. Journal of Public Economics, 89(9/10), 1879-1890

Krueger, A., Meyer, B., 2002. Labor Supply Effects of Social Insurance. In A. Auerbach and M. Feldstein (eds.), Handbook of Public Economics, vol. 4, pp. 2327-2392, North- Holland, Amsterdam 
Little, P., Williamson, I., Warner, G., Gould, C., Gantley, M., Kinmonth, A., 1997. Open Tandomised Trial of Prescribing Strategies in Managing Sore Throat. BMJ: British Medical Journal (International Edition), 314(7082), $722-727$

Little, P., Rumsby, K., Kelly, J., Watson, L., Moore, M., Warner, G., Fahey, T., Williamson, I., 2005. Information Leaflet and Antibiotic Prescribing Strategies for Acute Lower Respiratory Tract Infection A Randomized Controlled Trial. JAMA: Journal of the American Medical Association, 293(24), 3029-3035

Mainous, A.G., Zoorob, R.J., Oler, M.J., Haynes, D.M., 1997. Patient Knowledge of Upper Respiratory Infections: Implications for Antibiotic Expectations and Unnecessary Utilization. Journal of Family Practice, 45(1), 75-83

Neumark, T., Mölstad, S., Rosén, C., Persson, L., Törngren, A., Brudin, L., Eliasson, I., 2007. Evaluation of Phenoxymethylpenicillin Treatment of Acute Otitis Media in Children Aged 2-16. Scandinavian Journal of Primary Health Care, 25(3), 166-171

Pettersson-Lidbom, P., Skogman Thoursie, P., 2013. Temporary Disability Insurance and Labor Supply: Evidence from a Natural Experiment. Scandinavian Journal of Economics, 115(2), 485-507

Statistics Sweden. 2013. Statistical Database, available online at: http://www.scb.se/Pages/SSD/SSD_TreeView__340478.aspx

Swedish Social Insurance Agency. 2007. VAB - Vård Av Barn. Tillfällig föräldrapenning 1974-2006, Redovisar 2007:10

WHO, 2001. WHO Global Strategy for Containment of Antimicrobial Resistance, available at:

http://www.who.int/drugresistance/WHO_Global_Strategy_English.pdf?ua\%2 $\underline{0=1}$

WHO, homepage accessed April 14th 2014 at 9 am GMT +1 : http://www.who.int/drugresistance/AMR DC Resolutions/en/

Williamson, I., Rumsby, K., Benge, S., Moore, M., Smith, P., Cross, M., Little, P., 2007. Antibiotics and Topical Nasal Steroid for Treatment of Acute Maxillary 
Sinusitis: A Randomized Controlled Trial. JAMA: Journal of the American Medical Association, 298(21), 2487-2496

Ziebarth, N.R., Karlsson, M., 2010. A Natural Experiment on Sick Pay Cuts, Sickness Absence, and Labor Costs. Journal of Public Economics, 94(11/12), 1108-1122

Ziebarth, N.R., Karlsson, M., 2014. The Effects of Expanding the Generosity of the Statutory Sickness Insurance System. Journal of Applied Econometrics, 29(2), 208-230 